\title{
O MOTIVO EDÊNICO NO IMAGINÁRIO SOCIAL BRASILEIRO
}

\author{
José Murilo de Carvalho
}

O motivo edênico habita a imaginação nacional desde os primórdios da presença européia. A visão do país como natureza cristalizou-se definitivamente, e um tanto injustamente, no ufanismo de Afonso Celso. Este artigo tem dois objetivos. O primeiro é documentar, com dados de pesquisa de opinião pública, a surpreendente vitalidade do motivo edênico no Brasil de hoje. O segundo é sugerir que possível explicação do fenômeno pode estar naquilo que poderíamos chamar de motivo satânico, a visão negativa do povo, que também nos persegue de longa data.

\section{A razão edênica}

A presença do motivo edênico está bem documentada (Holanda, 1959; Cândido, 1981; Ventura, 1991). A visão paradisíaca da terra começou com os primeiros europeus que nela puseram o pé. Ela está presente já na carta de Caminha. Logo depois, em 1503, Américo Vespúcio, na carta que ficou conhecida como Mundus novus, dirigida a
O Brasil é uma paisagem.

(Nelson Rodrigues)

O meu sentimento nativista [...] sempre se doeu desta adoração da natureza. [...] eu não fir, nem mandei fazer, o céu e as montanhas, as matas e os rios. Já os achei prontos. (Machado de Assis)
Francesco de Medici, declara que, a existir o paraíso terreal, não estaria longe das terras que viu. Entre os cronistas quinhentistas, Gandavo supera Caminha em entusiasmo em sua História da Provincia de Santa Cruz, de1576. Para ele, "é esta província sem contradição a melhor para a vida do homem que cada uma das outras de América, por ser comumente de bons ares e fertilíssima, e em grã maneira deleitosa e aprazível à vista humana." (Gandavo, 1980, p. 81). 1 A província, continua, é revestida de alto e espesso arvoredo e regada com águas de muitas ribeiras, a terra é sempre verde, o clima de permanente primavera: "nunca nela se sente frio nem quentura excessiva" (idem, p. 82). Não seria difícil rastrear afirmações parecidas em outros cronistas do século XVI.

No século seguinte, o autor dos Diálogos das grandezas do Brasil prossegue no laudatório: "A terra é disposta para se fazer nela todas as agriculturas do mundo pela sua muita fertilidade, excelente clima, bons céus, disposição de seu temperamento, salutíferos ares, e outros mil atributos que se lhe ajuntam" (Diálogos, 1977 [1618], p. 32). Mais para o 
final do século, o padre Simão de Vasconcelos, em sua Crônica da Companbia de Jesus do Estado do Brasil, publicada em 1663, recorrendo ao testemunho de viajantes e baseado em suas próprias observações, afirma estar diante de um "espanto da natureza" e não hesita em dizer que "poderíamos fazer comparações ou semelhança de alguma parte sua com aquele paraíso da terra em que Deus nosso senhor, como em jardim, pôs o nosso pai Adam". Sem dúvida, diz o entusiasmado jesuíta, a terra brasílica era superior aos Campos Elísios. $\stackrel{2}{2}$

A expressão mais completa do edenismo está na História da América Portuguesa, de Rocha Pita, publicada em 1730. O livro, a primeira história do Brasil escrita por brasileiro então conhecida, de vez que a história de frei Vicente do Salvador, embora escrita em 1627, só foi publicada pela primeira vez em 1882, tem óbvio sentido apologético, é um hino patriótico, como diz Sílvio Romero. O próprio autor não esconde que escreve para aumentar a glória da pátria. O parecer de um censor da Academia Real da História Portuguesa, Antônio Rodrigues da Costa, aponta essa característica do livro ao dizer que parece "mais elogio ou panegírico, que história". Mas Rocha Pita não admite que, em nome do amor à pátria, tenha faltado à verdade. Diz ao leitor no Prólogo: "se entenderes que o compus [o livro] em aplausos e reverência do clima em que nasci, podes crer que são seguras e fiéis as notícias que escrevo porque os obséquios não fizeram divórcio com as verdades". $\underline{3} \mathrm{O}$ patriotismo brasileiro era justificado porque o autor baiano se via incomodado pelo fato de a própria metrópole desconhecer sua terra. Um dos censores do livro, o bispo Joseph Barbosa, reconhece o fato da ignorância das coisas brasílicas, chamando Pita de novo Colombo por ter sabido "descobrir outro mundo novo no mesmo mundo descoberto". Pita repete Gandavo, que admitira estar fazendo o elogio da terra como meio, diríamos hoje propaganda, para atrair imigrantes.

Modelo da visão do país como natureza, Rocha Pita merece citação mais distendida, que servirá também para transmitir o sabor de seu estilo:
Em nenhuma outra região se mostra o céu mais sereno, nem madruga mais bela a aurora; o sol em nenhum outro hemisfério tem raios tão dourados, nem os reflexos noturnos tão brilhantes; as estrelas são mais benignas e se mostram sempre alegres; os horizontes, ou nasça o sol, ou se sepulte, estão sempre claros; as águas, ou se tomem nas fontes pelos campos, ou dentro das povoações nos aquedutos, são as mais puras; é enfim o Brasil Terreal Paraíso descoberto, onde tem nascimento e curso os maiores rios; domina salutífero clima; influem benignos astros e respiram auras suavíssimas, que o fazem fértil e povoado de inumeráveis habitadores. (Rocha Pita, 1730, pp. 3-4)

A formação escolástica de Rocha Pita não lhe permitia ignorar a condenação que Aristóteles, seguido por Plínio e Cícero e por alguns padres da Igreja, como Santo Agostinho e Beda, tinham lançado sobre a "tórrida zona", como sendo inabitável. Mas ele descarta saudavelmente tais opiniões alegando simplesmente que seus autores não tinham da terra experiência direta, em outras palavras, que não sabiam do que estavam falando (o que não impediu que a opinião de Aristóteles ainda continuasse a influenciar a visão de europeus sobre o trópico). 4 Aristóteles não obstante, o texto de Rocha Pita tornou-se a formulação clássica de nosso ufanismo edênico, repetido com variações desde a "Canção do exílio" até o hino nacional, passando pelo Porque me ufano do conde de Afonso Celso.

Antes de chegarmos ao romantismo e a Gonçalves Dias, no entanto, houve outra conjuntura histórica em que foram retomadas as discussões sobre as excelências da terra brasílica. Trata-se de momento privilegiado para a manifestação do orgulho nacional, aquele que vai de 1820 , data da revolta liberal do Porto, até 1822, data da independência. Neste breve período deu-se, ao lado da guerra política, aquilo que o cônego Luís Gonçalves dos Santos, o padre Perereca, chamou muito adequadamente de "guerra literária" entre brasileiros e portugueses. A arma usada nessa guerra foram panfletos políticos, cujo estudo

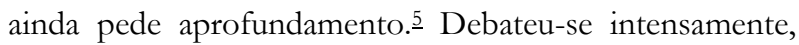
primeiro, se D. João devia permanecer no Brasil ou retornar a Portugal. Após o regresso do rei, a discussão girou em torno das vantagens e desvantagens da manutenção da união entre os dois reinos.

Do ponto de vista que aqui me interessa, o panfleto mais importante é o do próprio padre Perereca, intitulado "Justa retribuição dada ao compadre de Lisboa". O cônego 
responde a outro panfleto intitulado "Primeira carta do compadre de Lisboa", vitriólico ataque ao Brasil. O compadre de Lisboa, Manuel Fernandes Tomás, atacara o clima e a gente do Brasil para desqualificar o país como sede da monarquia. Dissera, repetindo Aristóteles, que o país, por estar na zona tórrida, tinha clima ardente e pouco sadio. Só os africanos podiam suportar, e isto por tempo limitado, os "dardejantes raios de uma zona abrasadora". Além disso, continuava, a população do país estava reduzida "a umas poucas hordas de negrinhos pescados na Costa d'África". O país é "selvagem, inculto, e terra de macacos, dos pretos e das serpentes". Padre Perereca e outros panfletários foram tomados de indignação nativista diante dos insultos do compadre lisboeta. O padre foi buscar em várias autoridades, brasileiras e estrangeiras, argumentos para refutar a posição do "charlatão incivil e furioso" de Lisboa. Menciona a Corografia do Brasil (certamente referindo-se à Corografia brazílica de Manuel Aires do Casal, publicada em 1817), osEstudos do bem comum (referência à obra de José da Silva Lisboa, visconde de Cairu), as memórias de D. Caetano Brandão, Langsdorff, o naturalista inglês Clarke e os quadros de Maximiliano de Neuwied. Cita ainda, sem mencionar nomes, outros cronistas coloniais, permitindo que se deduza que já se construía uma tradição, um imaginário coletivo, em torno do motivo edênico.

Com base nessas autoridades, o cônego aponta a excelência do clima, de "primavera completa", as belezas naturais, a fertilidade do solo, as riquezas minerais. De Cairu aproveita outro tema familiar dentro da visão edênica: a ausência de flagelos naturais, secas, terremotos, tufões, epidemias. Conclui que, apesar de não ser o Brasil o paraíso terreal, como queria o missionário jesuíta (provável referência a Simão de Vasconcelos), se parece muito com ele e é sem dúvida o paraíso pagão, "os Elísios deste Novo Mundo chamado América" (p. 27). Basta que se lhe aumente a população para ser "o maior império, o mais florente e poderoso da terra" (pp. 27-28). Às vésperas da independência, a grandeza natural do país e a abundância de suas riquezas já se tinham transformado, projetadas para o futuro, em fundamento para a justificação da criação de um vasto império, de uma grande potência. $\mathrm{O}$ mais forte argumento dos que defendiam a continuação do Reino Unido era exatamente a possibilidade de se criar na América um grande e poderoso império. $\underline{6}$

Tais panfletos são importantes para mostrar a continuidade da temática edênica. Mas sua natureza conjuntural lhes deu vida efêmera, não permitindo que se tornassem instrumento de socialização da geração que surgia com a independência. Os textos da época da independência que tiveram maior influência sobre a maneira de ver a natureza foram os de um estrangeiro, Ferdinand Denis. Em dois livros, um de 1824, o outro de 1826, Denis sugeriu que a originalidade da literatura brasileira se deveria basear na descrição da natureza tropical e nos costumes (exóticos) indígenas. $\stackrel{-}{-} \mathrm{O}$ romantismo nacional, nas pegadas de Domingos José Gonçalves de Magalhães, seguiu de perto as recomendações de Denis mas tinha raízes muito mais antigas em que se alimentar. E certamente teve grande êxito em difundir o motivo edênico. Mesmo hoje, quem não conhece de cor pelo menos algumas estrofes da "Canção do exílio" de Gonçalves Dias? A mais famosa delas, "Nosso céu tem mais estrelas/nossas várzeas têm mais flores/nossos bosques têm mais vida/nossa vida mais amores", foi transplantada para a letra do hino nacional escrita por Joaquim Osório Duque Estrada na primeira década do século. Ela é puro Rocha Pita, revivido quase duzentos anos depois.

O conde de Afonso Celso é, assim, apenas mais um elo nessa cadeia ininterrupta de tradição edênica. Até mesmo a expressão "ufania nacional" já tinha aparecido nos panfletos da independência. A fama de criador do ufanismo atribuída ao conde justifica-se apenas pelo fato de ter ele sistematizado de maneira didática as razões de orgulho nacional baseadas nas belezas e riquezas naturais. Em seu livro, publicado em 1900 para celebrar o quarto centenário da viagem de Cabral, são analisadas, uma a uma, a grandeza do território, as belezas naturais, as riquezas, o clima e a ausência de calamidades. Como vimos, tudo isto já estava presente na tradição brasileira. $O$ conde conhecia essa literatura, mesmo que fosse via o Jornal de Timon de João Francisco Lisboa, cuja primeira edição completa é de 186465. Cita, via Lisboa, a referência de Américo Vespúcio ao 
paraíso terreal, nomeia vários dos cronistas coloniais, sobretudo Simão de Vasconcelos, cita parte do trecho de Rocha Pita que reproduzi acima, também citada por Lisboa. Menciona estrangeiros, como Humboldt e Lamberg. E não deixa de reproduzir a famosa estrofe de Gonçalves Dias. É assim que, do começo ao final do Império, mantém-se viva a tradição edênica. Mantém-se pelo menos entre a elite letrada, pois não há indicação de sua vigência entre a população. É provável que não existisse. $\mathrm{Na}$ época, o principal mecanismo de propagação de imagens nacionais era a educação primária. A crermos no depoimento de José Veríssimo (1906), sem dúvida exagerado, durante o Império essa educação era totalmente desnacionalizada, não sendo provável que tivesse sido transmissora de patriotismo de qualquer espécie, além de atingir parcela muito pequena da população. $\underline{8}$

A importância do livro de Afonso Celso pode ter sido exatamente a de popularizar Rocha Pita. As edições do livro sucederam-se rapidamente. Embora não existam estudos a respeito, é provável que ele tenha sido adotado nas escolas primárias e secundárias. Tal adoção teria sido coerente com as tentativas, feitas após a proclamação da República, de promover a educação cívica das crianças via textos escolares. Envolveram-se nesse esforço alguns dos principais escritores da época. Entre os mais ativos, estiveram Sílvio Romero, Olavo Bilac, Coelho Neto, Manoel Bomfim, Afrânio Peixoto. Curiosamente, alguns desses autores, como Sílvio Romero, passavam para as crianças imagem muito mais positiva do país e de sua gente do que a que adotavam em suas obras para adultos. Alguns deles também se juntaram a Afonso Celso na formação das ligas de defesa nacional na segunda década do século.?

É provável que essa literatura cívica tenha penetrado na escola primária e se tornado responsável pela difusão do motivo edênico no imaginário popular brasileiro. O certo é que ele se difundiu e criou raízes profundas. Tão profundas que sobrevive até hoje e com boa saúde.

\section{A sobrevivência do edenismo}

A prova da sobrevivência pode ser encontrada em duas pesquisas de opinião pública recentemente realizadas. Uma das pesquisas tem âmbito nacional e foi feita por empresa especializada; a outra, realizada por instituições acadêmicas, limita-se à Região Metropolitana do Rio de Janeiro. Ambas abrangem temática variada. Aqui aproveito apenas as perguntas que dizem respeito ao tema de que me ocupo. $\underline{10}$

Uma pergunta boa para iniciar a discussão é a que busca saber se os entrevistados têm orgulho de ser brasileiros. As respostas estão na Tabela 1.

Tabela 1

Orgulho de ser brasileiro

\begin{tabular}{|c|c|}
\hline $\begin{array}{c}\text { Sente por ser } \\
\text { brasileiro }\end{array}$ & $\%$ \\
\hline muito orgulho & 59,6 \\
\hline algum orgulho & 27,4 \\
\hline $\begin{array}{c}\text { não sente } \\
\text { orgulho }\end{array}$ & 6,8 \\
\hline $\begin{array}{c}\text { sente vergonha } \\
\text { NS/NR }\end{array}$ & 1,8 \\
\hline total & 100,0 \\
\hline
\end{tabular}

Fonte: Cpdoc/ISER (1997).

Colocada a pergunta desta maneira, é muito grande a proporção de ufanistas. A pesquisa $\mathrm{VP} / V_{e j a}$ dá resultados parecidos, embora não distinga entre "muito orgulho" e "algum orgulho". Segundo ela, um total de $84 \%$ dos entrevistados acham que ser brasileiro é motivo de orgulho e apenas 5\% julgam tal fato ser motivo de vergonha, números quase idênticos aos da pesquisa do Rio (Veja, 10/1/1996, p. 49). Esses dados indicam uma taxa de 
orgulho que se coloca entre as mais altas do mundo. Segundo dados do World value survey para 1990, apenas Estados Unidos e Irlanda registram porcentagens de "muito orgulho" bem acima da brasileira. Taxas comparáveis são as do Canadá, México, África do Sul. Muito abaixo estão as da Holanda, Alemanha, Japão
(Ingelhart, 1997, p. 304). Mas pode-se suspeitar que uma pergunta colocada em termos assim tão amplos induza respostas ritualísticas. Convém desdobrar as respostas segundo algumas variáveis para explorar possíveis diferenças por trás do aparente monolitismo patriótico. A Tabela 2 faz o controle por nível educacional.

Tabela 2

Orgulho de ser brasileiro por escolaridade (\%)

\begin{tabular}{|c|c|c|c|c|}
\hline $\begin{array}{c}\text { Sente por } \\
\text { ser } \\
\text { brasileiro }\end{array}$ & $\begin{array}{c}\text { Até 4a } \\
\text { série do } \\
\text { 1o. grau }\end{array}$ & $\begin{array}{c}\text { Da 5a à } \\
\text { 8a séries }\end{array}$ & $\begin{array}{c}\text { 2o. grau } \\
\text { incompleto/ } \\
\text { completo }\end{array}$ & $\begin{array}{c}\text { 3o. grau } \\
\text { incompleto/ } \\
\text { completo }\end{array}$ \\
\hline $\begin{array}{c}\text { muito } \\
\text { orgulho }\end{array}$ & 69,8 & 58,2 & 52,5 & 52,5 \\
\hline $\begin{array}{c}\text { algum } \\
\text { orgulho }\end{array}$ & 20,0 & 28,5 & 31,9 & 33,5 \\
\hline $\begin{array}{c}\text { não sente } \\
\text { orgulho }\end{array}$ & 4,7 & 6,5 & 9,0 & 8,9 \\
\hline $\begin{array}{c}\text { sente } \\
\text { vergonha }\end{array}$ & 4,2 & 5,2 & 4,8 & 1,3 \\
\hline NS/NR & 1,3 & 1,6 & 1,8 & 3,8 \\
\hline total & 100,0 & 100,0 & 100,0 & 100,0 \\
\hline & $(\mathrm{N}=451)$ & $(\mathrm{N}=572)$ & $(\mathrm{N}=398)$ & $(\mathrm{N}=158)$ \\
\hline
\end{tabular}

Fonte: Cpdoc/ISER (1997).

A Tabela 2 introduz informações algo surpreendentes. A primeira é que, em geral, o grau de escolaridade não afeta de modo significativo o fato de se ter ou não orgulho do país. Mas se se leva em conta apenas a resposta "muito orgulho", aparece uma diferença significativa $(17,3 \%)$ entre os menos educados e os mais educados, no sentido de que os primeiros são mais patriotas que os últimos. Este resultado não surpreende, pois é razoável supor que entre os mais educados o senso crítico esteja mais desenvolvido, ou seja, quanto mais se conhece o país menos dele se gosta. O que surpreende é que o grande corte se dá a partir da quarta série do primeiro grau. Entre os que completaram da quinta à oitava séries, os muito orgulhosos caem de
69,8\% para 58,2\%; o segundo corte, menor, se dá entre os que completaram parte do segundo grau. Nesta faixa os muito orgulhosos caem para 52,5\%. Ter alguma educação superior não faz diferença alguma em relação ao segundo grau em matéria de ter muito orgulho do país. Ao descumprir a obrigação de dar educação primária completa, os governos brasileiros parecem adivinhar o efeito que ela pode ter em aguçar o senso crítico.

Pode-se perguntar também em que medida a idade afeta o orgulho pelo país. O padrão de respostas é muito semelhante ao da Tabela 2. A diferença de opiniões por idade se dá apenas quando se toma a resposta "muito 
orgulho". A geração mais velha, a partir de 40 anos, é mais patriota do que as mais novas. O resultado não deixa de ser intrigante. $\mathrm{O}$ fato político que marcou mais profundamente os últimos 60 anos foi o golpe de 1964, seguido dos 20 anos de governo militar. São exatamente os que nasceram antes do golpe e que, portanto, sofreram mais pesadamente a repressão os que demonstram maior orgulho do país. Como explicar isso? O mais razoável seria esperar desencanto da parte dessa geração. A não ser que o nacionalismo da década de 50 estivesse tão arraigado que conseguiu sobreviver à prova do período militar. Por outro lado, era de esperar que as gerações posteriores ao golpe, bombardeadas com intensa propaganda do governo, e submetidas ao ensino de Moral e Cívica, exibissem maior ufanismo. O fato de que isto não seja verdade talvez signifique que não haja melhor socialização política do que aquela transmitida pela ação, como a que se deu durante as lutas nacionalistas.

Variáveis como gênero, religião, grau de informação (medido por leitura de jornais), grau de participação política (em greves, passeatas e outros tipos de protesto), mobilidade social, grau de associativismo têm efeito pequeno sobre a taxa de orgulho. Merece referência apenas o fato de que, quando se trata da resposta "muito orgulho", os seguidores das religiões afro-brasileiras, umbanda e candomblé, tendem a ter mais orgulho do que os seguidores de outras religiões. $\mathrm{O}$ associativismo também faz diferença quando a resposta é "muito orgulho". Os que se filiam mais a sindicatos e associações profissionais e de beneficência têm muito mais orgulho $(77 \%)$ do que os que não se associam (59\%). O oposto acontece com os que têm maior participação política. Entre os que têm alta participação, 45\% responderam sim a "muito orgulho", contra $60 \%$ dos que têm baixa participação.

Indo agora direto ao tema edênico, pediu-se nas duas pesquisas que o entrevistado indicasse três motivos que o levavam a ter orgulho do Brasil. Além de especificar as respostas, buscava-se ainda forçar as pessoas a raciocinarem um pouco e fugirem do possível ritualismo embutido nas respostas à pergunta anterior. As respostas estão na Tabela 3.

Tabela 3

Motivos de orgulho de ser brasileiro (\%)*

\begin{tabular}{|c|c|c|c|c|c|}
\hline Motivos & VP/ & CPDOC/ & VP/ & CPDOC/ & CPDOC/ \\
VEJA 1 & $\underline{\text { ISER1 }}$ & VEJA 2 & ISER2 & ISER3 \\
\hline natureza & 25 & 26,0 & 25 & 19,8 & 34,8 \\
\hline caráter do povo & 20 & 11,3 & 21 & 8,8 & 15,5 \\
\hline características do país & 10 & 13,8 & 9 & 9,3 & 16,3 \\
\hline esporte/música/carnaval & 11 & 6,8 & 7 & 5,2 & 9,1 \\
\hline \multirow{2}{*}{ outros } & 3 & 15.7 & 4 & 10,7 & 18,8 \\
\hline nenhum & 8 & 2,5 & 7 & 3,1 & 5,4 \\
\hline NS/NR & 23 & 23,7 & 27 & 43,1 & - \\
\hline total & 100.0 & 100.0 & 100.0 & 100.0 & 100.0 \\
\cline { 2 - 6 } & $(\mathrm{N}=1976)$ & $(\mathrm{N}=1579)$ & $(\mathrm{N}=1962)$ & $(\mathrm{N}=4734)$ & $(\mathrm{N}=2696)$ \\
\hline
\end{tabular}

\footnotetext{
* Foi pedido aos entrevistados que apontassem três motivos de orgulho. Em VP/VEJA 1 e CPDOC/ISER 1 levou-se em conta apenas a primeira resposta. Em VP/VEJA 2 e CPDOC/ISER 2 fez-se a média das três respostas. Como, no caso de CPDOC/ISER 2, aumentassem muito as respostas NS/NR, elas foram eliminadas em CPDOC/ISER 3. O menor aumento das respostas NS/NR em VP/VEJA 2 se deve ao fato de que elas só foram computadas uma vez, isto é, só era pedido o segundo motivo a quem tivesse dado o primeiro e só era pedido o terceiro a quem tivesse dado o segundo. No caso da pesquisa VP/VEJA, foi feita a soma de algumas respostas apresentadas na tabela que foi publicada. Fontes: VP/Veja e Cpdoc/ISER (1997).
} 
Incluo em "natureza" todas as respostas que se referem às belezas naturais, inclusive a das mulheres (corpo é natureza). Alguns exemplos de respostas: natureza, natureza maravilhosa, paisagem, terra maravilhosa, terra santa, Amazônia, florestas, montanhas, pantanal, cachoeiras, orla marítima, o verde, o sol, ar puro, a fauna, a flora, aspecto geográfico, beleza física, beleza geográfica, beleza natural, beleza das praias, praias do Nordeste, país mais bonito do mundo, país abençoado, país belíssimo, fertilidade do solo, tudo que planta dá, terra rica, país mais rico do mundo, riquezas naturais, riquezas minerais, país continental, extensão territorial, grandeza do país, grandiosidade, cidade maravilhosa, clima tropical, clima bom, não ter terremoto, furacão, tufão, vulcão, beleza do povo, as mulheres bonitas. Isto é, o item inclui todas as respostas que se enquadram na lista sistematizada por Afonso Celso.

"Caráter do povo" inclui os traços de personalidade do brasileiro considerados positivos e pessoas exemplares. Exemplos: povo solidário, trabalhador, unido, esforçado, cordial, artístico, hospitaleiro, bom, alegre, pacífico, batalhador, ordeiro, competitivo, simples, acolhedor, amigo, amistoso, amoroso, carinhoso, camarada, capaz, honesto, humanitário, humano, religioso, inteligente, livre, festivo, feliz, a família, a mãe de 92 anos, Getúlio Vargas, Betinho, Ayrton Senna, Juscelino Kubitschek, Xuxa etc. "Características do país" incluem traços positivos não relacionados à natureza, isto é, que são conquistas humanas. Exemplos: ausência de discriminação racial, de terrorismo, de conflitos, de pena de morte, país hospitaleiro, paz, liberdade de opinião, de expressão, de religião, democracia, progresso, desenvolvimento, campanha da fome, campanha Viva Rio, o Plano Real etc. "Esporte e música" são auto-explicativos e incluem também artes, artistas, Carnaval.

Naturalmente, houve respostas que não se encaixavam nas categorias acima. Mas não constituíam um grupo suficientemente homogêneo, coerente e significativo para justificar a criação de categoria especial. Apenas como ilustração, cito algumas: ter nascido aqui, ser brasileiro, gostar do país, ter saúde, ser mulher, os estrangeiros adoram o Brasil, passear, Rio de Janeiro, Curitiba, o Cristo Redentor, a bandeira, a religião, a cerveja no fim de semana, lazer, ser feliz etc.

A primeira revelação da tabela é que, apesar de $87 \%$ dos entrevistados terem dito que tinham orgulho de ser brasileiros, em torno de 23\%, nas duas pesquisas (VP/Veja 1 e Cpdoc/ISER 1), não souberam indicar, na primeira opção, um motivo sequer para tal orgulho. Computando-se as três razões para orgulho, a porcentagem dos que não conseguiram responder sobe para a $43 \%$ (Cpdoc/ISER2). Isto em momento da vida nacional que, se não era de euforia, também não era de depressão. Segundo a pesquisa VP/Veja, 45\% dos entrevistados achavam que o país estava melhorando e só $31 \%$ que estava piorando (Veja, 10/1/1996, p. 51). Confirma-se, desse modo, o caráter ritualístico das respostas à primeira pergunta $(\underline{\text { Tabela } 1}) \cdot \underline{11}$

Dito isto, a grande surpresa: ao final do século XX, 264 anos após Rocha Pita, 96 anos depois da publicação do livro do conde de Afonso Celso, o motivo edênico ainda predomina entre os entrevistados que conseguem apontar alguma razão para seu orgulho, tanto na pesquisa nacional como na do Rio de Janeiro. Independentemente das várias maneiras de tabular as respostas, o motivo edênico está sempre em primeiro lugar. No caso da pesquisa Cpdoc/ISER, ele representa, consistentemente, o dobro do segundo motivo alegado, características do país. E o que é mais típico: entre essas características, em nenhuma das duas pesquisas aparecem as instituições políticas do país, os três poderes, o sistema representativo etc., como acontece em geral em países de tradição democrática. $\frac{12}{\mathrm{~A}}$ única diferença significativa entre as duas pesquisas é a menor valorização do povo e uma visão um pouco mais positiva das características do país encontradas entre os entrevistados da Região Metropolitana do Rio de Janeiro.

Surpresa e preocupação. Como é que, 174 anos após a independência, os brasileiros ainda não conseguem encontrar razões para seu orgulho patriótico que tenham a ver com conquistas nacionais e não com fatores sobre os quais não têm controle? Pois, como diz Machado de Assis, 
citado na epígrafe deste trabalho, nós não fizemos os céus, as montanhas, as matas e os rios. Muito menos protegemos o país de terremotos, vulcões e furacões. Machado reclamava dos estrangeiros que visitavam o Brasil e só viam o "pays féerique". Ao mostrar a cidade a um visitante estrangeiro, este só se lembrou de fazer um comentário: "Mas que natureza que vocês têm!". Tal atitude, queixa-se Machado, pisava o homem e sua obra, excluía qualquer idéia de ação humana. $\frac{13}{}$ Pode-se imaginar a decepção do cronista se verificasse que ela é até hoje, talvez mais ainda do que em sua época, compartilhada pelos próprios brasileiros. Sua indignação com o desprezo pelo país reaparece quase 80 anos depois em Nelson Rodrigues, que se exprime com a contundência que lhe era própria: "Ah, o Brasil não é uma pátria, não é uma nação, não é um povo, mas uma paisagem." (Rodrigues, 1997, p. 14). A mais perfeita representação do Brasil como paisagem talvez seja um "Nu deitado" de Di Cavalcanti, da década de 1930. O pintor retrata uma mulata nua cujas curvas se confundem com as formas da natureza. Mulher e natureza se fundem.

Antes de buscar possíveis explicações para nosso edenismo, pode-se perguntar se há fatores específicos que afetam as respostas. Aqui os resultados limitam-se à pesquisa Cpdoc/ISER. A cor das pessoas não produz diferenças significativas. No que se refere a religião, há ligeira tendência entre os mediúnicos, seguidores da umbanda, candomblé e espiritismo, de serem mais edenistas que os outros. O fato talvez se deva à maior presença da natureza nos cultos afro-brasileiros. Não seria de estranhar que tal presença se transferisse para o campo do civismo. A idade das pessoas produz diferenças. A geração mais velha, de mais de 55 anos, é a que menos se refere ao motivo edênico (21\% na primeira resposta, 15\% na combinação das três) e a geração mais nova (de 16 a 25 anos) é a que mais nele acredita $(33 \%$ e $25 \%$, respectivamente). Razão para preocupação ainda maior, pois aparentemente o edenismo não só está vivo como revela sintomas de fortalecimento. A geração mais nova é também a que menos vê pontos positivos nas características país e a que mais valoriza esporte, música e Carnaval. A geração da redemocratização não parece ter vivido a mudança política como conquista nacional de que se pudesse orgulhar. Estranhamente, nem a campanha pelo impedimento de Collor, tão recente e tão marcante pela presença dos jovens, é mencionada como motivo de orgulho.

Finalmente, fez-se o controle por educação, fator que em tese pode ser visto como o mais importante para determinar as razões de orgulho (Tabela 4).

Nesta tabela há duas curvas opostas, uma previsível, a outra surpreendente. A previsível é a correlação negativa entre educação e capacidade de mencionar motivos de orgulho. Entre os menos educados (até a $4^{\text {a }}$ série) há o dobro de pessoas, em relação aos mais educados, incapazes de mencionar qualquer motivo de orgulho. Os que têm mais orgulho são exatamente os que têm mais dificuldade em o justificar. A curva surpreendente é o aumento sistemático do motivo edênico na proporção em que aumenta a educação. Os edenistas são o dobro entre os que têm educação secundária ou superior. Se os mais educados, como vimos, tendem a ser menos ufanistas, tendem, em contrapartida, a ser muito mais edenistas. $\mathrm{E}$ isto inclui os que têm educação universitária, os mais edenistas de todos. Quanto mais educada a pessoa, mais concentra seus motivos de orgulho em fatores naturais. Tal tendência é confirmada pelo fato de que os mais bem informados, isto é, os que mais lêem jornais, também são mais edenistas do que os menos informados. Como explicar isso? O fato seria devido ao conteúdo da educação? Estaria o motivo edênico tão enraizado nos textos escolares? Seria efeito da educação moral e cívica e da propaganda patrioteira dos regimes militares?

No que se refere à propaganda em sentido estrito, a resposta deve ser negativa. Estudo recente de Carlos Fico (1997) mostra que a AERP (Assessoria Especial de Relações Públicas), criada no governo Médici, e sua sucessora, a ARP (Assessoria de Relações Públicas), do governo Geisel, enfatizavam, sim, o otimismo em relação ao país. Mas as razões dadas para o otimismo não eram edênicas. Alguns dos temas centrais, ou idéias-força, da propaganda tinham a ver com as noções de construção e 
transformação do Brasil, como o atestam as campanhas intituladas "Você constrói o Brasil", de 1972, ou "O Brasil é feito por nós", de 1976. Incentivavam a união, o amor, a solidariedade, a fraternidade, enalteciam o homem brasileiro, os heróis nacionais, os acontecimentos históricos, não a natureza. Tudo era, evidentemente, mistificação, tentativa de carrear apoio para o governo militar, de despolitizar a população. Mas o importante para o ponto em discussão é o fato de que não era edênica a propaganda. Nisto, aliás, ela seguia o exemplo da propaganda do Estado Novo e da literatura infantil que desde o início da República buscava chamar a atenção para pessoas e feitos. 14 O criador da AERP, coronel Otávio Costa, em depoimento a Carlos Fico, disse explicitamente ter lutado "feito um leão" contra a tendência à exaltação das belezas nacionais representada na época pelos programas de televisão apresentados por Amaral Neto (Fico, 1997, p. 137). Portanto, o edenismo recente não pode ser debitado à propaganda militar. $\mathrm{O}$ que estava presente, sim, nessa propaganda era a derivação política do edenismo, a idéia de Brasil grande potência, já presente à época da independência sob a forma de Brasil "poderoso império".

Tabela 4

Motivos de orgulho de ser brasileiro por escolaridade (\%)

\begin{tabular}{|c|c|c|c|c|}
\hline Motivos & $\begin{array}{c}\text { Até 4a } \\
\text { série do 1o. } \\
\text { grau }\end{array}$ & $\begin{array}{c}\text { Da 5a à 8a } \\
\text { séries }\end{array}$ & $\begin{array}{c}\text { 2o grau } \\
\text { incompleto/ } \\
\text { completo }\end{array}$ & $\begin{array}{c}\text { 3o grau } \\
\text { incompleto/ } \\
\text { completo }\end{array}$ \\
\hline natureza & 13,2 & 20,0 & 24,0 & 26,8 \\
\hline caráter do povo & 6,5 & 7,2 & 9,5 & 19,2 \\
\hline caráter do país & 9,2 & 8,1 & 10,8 & 10,4 \\
\hline esporte/música & 3,2 & 6,4 & 6,1 & 4,4 \\
\hline outros & 13,1 & 9,1 & 10,4 & 10,4 \\
\hline nenhum & 4,1 & 2,7 & 2,8 & 2,3 \\
\hline NS/NR & 50,7 & 46,5 & 36,4 & 26,5 \\
\hline total & 100,0 & 100,0 & 100,0 & 100,0 \\
\cline { 2 - 5 } & $(\mathrm{N}=1355)$ & $(\mathrm{N}=1715)$ & $(\mathrm{N}=1190)$ & $(\mathrm{N}=473)$ \\
\hline
\end{tabular}

Fonte: Cpdoc/ISER (1997). Foram somadas as três respostas.

O ensino, no entanto, é outra história. Pesquisa feita no Maranhão na década de 70 (governo Geisel) mostra que a TVE, encarregada do ensino de Moral e Cívica da $4^{\text {a }}$ à $8^{a}$ séries do $1^{\circ}$ grau, transmitia uma visão paradisíaca do país (Bomeny, 1981, cap. III). O paraíso, no caso, não se limitava à natureza; abrangia também as qualidades do povo (bom, pacífico, hospitaleiro) e do governo (bom, patriota, competente). Mas incluía a natureza, pois a TVE utilizava os programas de Amaral Neto, detestados pelo coronel Otávio Costa. A propaganda tinha grande eficácia. Redações dos alunos indicaram à pesquisadora que estes compravam todo o pacote publicitário, natureza, povo e governo. Um aluno diz que apresentaria o país a um estrangeiro dizendo que ele era "uma espécie de paraíso infinito, porque é calmo, bonito etc. Eu tenho orgulho do meu país." (Bomeny, 1981, p. 77). 
Outra hipótese que talvez não seja de todo estapafúrdia para explicar o maior edenismo dos mais jovens é que ele teria a ver com a moda, surgida na campanha pela eleição direta, de se cantar o hino nacional. Fafá de Belém emocionou a todos com sua versão particular do hino, que passou, daí em diante, a ser cantado a propósito de qualquer coisa, quando antes só era ouvido em cerimônias oficiais, rituais cívicos e nas desafinadas vozes dos jogadores da seleção de futebol. A juventude o cantou profusamente na campanha do impedimento de Collor. Ora, o hino nacional é de longe mais edênico do que o Porque me ufano. Tome-se a primeira estrofe, por exemplo. Para começar, o brado retumbante do povo heróico é invenção. Quem bradou foi D. Pedro. Mas o pior é que o ouvinte do brado foi o palco, foi a natureza, foram as margens do Ipiranga. D. Pedro gritou para as margens (que certamente não retumbaram em resposta). Mais ainda, a referência à liberdade, uma conquista humana, feita logo a seguir, aparece via metáfora natural: a liberdade é o sol cujos raios brilham no céu. Mais à frente, surge de novo o céu risonho e límpido e o gigante belo, impávido, colosso. Colosso pela natureza. A grandeza do futuro é garantida pelo gigantismo natural. Mas não basta: o país está deitado em berço esplêndido, iluminado ao sol do novo mundo. E vem a seguir a citação da "Canção do exílio". Por fim, o símbolo de amor eterno é o Cruzeiro do Sul, que aparece, aliás, duas vezes no hino. Não seria de estranhar que a cantoria mais freqüente do hino tenha contribuído para a absorção, mesmo inconsciente, do edenismo. Mas esta explicação, embora plausível, certamente não é satisfatória. Continua aberta a questão.

\section{A razão satânica}

Numa terra radiosa, vive um povo triste. (Paulo Prado, Retrato do Brasil)

Além de possíveis razões tópicas para a persistência do motivo edênico, como as relacionadas com educação, religião e hino nacional, podemos imaginar ainda razões mais duradouras de natureza histórica e cultural. Poder-se- ia perguntar, por exemplo, se o predomínio edênico não teria a ver com a ausência de outras razões de orgulho. A ausência mais óbvia, porque também parte de nosso imaginário, seria a da inadequação do elemento humano que habita o país. A esta inadequação poderíamos chamar, por oposição à razão edênica, e com algum exagero, de razão satânica.

É rica a literatura sobre a descoberta e colonização da América que discute a natureza do homem americano em geral e brasileiro em particular. Antonello Gerbi analisou o debate desde Buffon até o final do século XIX (Gerbi, 1996). Afonso Arinos de Melo Franco (1937) fez um levantamento do imaginário europeu a respeito dos índios brasileiros, desde Vespúcio até a Revolução Francesa. Assim como se disputava sobre a qualidade da terra e do clima, também era motivo de debate a qualidade do homem, tanto o nativo como o imigrado, variando as avaliações entre positivas e negativas. As últimas referiamse, sobretudo, aos imigrados europeus. Nos Diálogos das grandezas do Brasil, depois que Brandônio descreve as maravilhas da terra, é interpelado por Alviano, que lhe pergunta como se explicaria, então, a carestia de todos os produtos. A resposta de Brandônio: "É culpa, negligência e pouca indústria de seus moradores" (Diálogos, 1977, p. 33). São conhecidas as queixas freqüentes dos padres jesuítas e dos donatários contra o envio para o Brasil de criminosos e prostitutas. A escravidão foi também acusada de corromper senhores e escravos. Alguns, como o jesuíta Jorge Benci, atribuíam a depravação à própria raça negra. Para não espichar a história, salto logo para a época da independência. Vimos que alguns autores de panfletos só viam no país hordas de negrinhos pescados nas costas d'África. Na segunda metade do século, a inferioridade brasileira ganhou revestimento cientificista graças às teorias racistas aceitas, em maior ou menor grau, por pensadores do porte de Sílvio Romero, Euclides da Cunha, Nina Rodrigues. Indicadora da mentalidade da virada do século, o momento em que Afonso Celso publicava seu livro, é a frase de um personagem de Araripe Júnior em livro de 1909, significativamente chamado Diálogos das novas grandezas do Brasil: "País perdido, este Brasil! Bem diz Sílvio 
Romero que nesta terra tudo é grande, só o homem nada vale." (Araripe Júnior, 1909, p. 103). Ao final da Primeira República, Paulo Prado produziu uma das mais pessimistas visões do brasileiro. Todos conhecem a primeira sentença de seu Retrato do Brasil: "Numa terra radiosa, vive um povo triste", marcado pela cobiça e pela luxúria (Prado, 1928). 15 A avaliação de Prado é a mesma do poeta irlandês Thomas Moore, que visitou a América no início do século XIX. Rejeitando a visão negativa da natureza americana, Moore insiste, no entanto, no pessimismo quanto à população: à grandiosidade da natureza correspondia uma população selvagem, fraca, repugnante, idiota (Gerbi, 1996, pp. 254-257).

As pesquisas de VP/Veja e Cpdoc/ISER incluem perguntas que permitem avaliar a auto-imagem do brasileiro de hoje. $\mathrm{Na}$ da $\mathrm{VP} / V_{e j a}$, a maioria dos entrevistados (53\%) avalia negativamente a colonização portuguesa. Além disso, africanos e asiáticos são vistos como tendo tido influência mais negativa que positiva. Vimos que na pesquisa Cpdoc/ISER o caráter do povo aparece em discreto terceiro lugar como razão para se ter orgulho do país. Outras perguntas desta última pesquisa buscaram esclarecer o conteúdo da auto-avaliação nacional. Pediu-se aos entrevistados que selecionassem, de uma lista de adjetivos, aqueles que, em sua opinião, melhor definiam os brasileiros e os cariocas. O resultado está na Tabela 5 .

Tomando as características que obtiveram a indicação de $50 \%$ ou mais dos entrevistados, vê-se que as que melhor descrevem os brasileiros são, nesta ordem, sofredor, trabalhador, alegre, conformado. As mesmas características definem o carioca mas em outra ordem: alegre, sofredor, conformado, trabalhador. Confirmam-se os estereótipos sobre o carioca: em relação aos outros brasileiros, ele é mais alegre, menos trabalhador, mais malandro, menos sofredor. Mas também, sinal dos tempos, e fora dos estereótipos, o carioca é visto por si mesmo como menos pacífico, mais violento. Comparando-se esses resultados com os da pesquisa VP/Veja, vê-se que as diferenças não são grandes. Segundo a última, as quatro características dos brasileiros mais lembradas são, pela ordem, trabalhador/lutador, divertido, acomodado e solidário. Sofredor vem logo após solidário (Veja, 10/1/1996, p. 53).무

Tabela 5

Imagem dos brasileiros e cariocas (\%)

\begin{tabular}{|c|c|c|}
\hline Imagem & Brasileiros & Cariocas \\
\hline sofredor & 74,1 & 54,9 \\
\hline trabalhador & 69,4 & 49,7 \\
\hline alegre & 63,3 & 70,4 \\
\hline conformado & 61,4 & 51,3 \\
\hline batalhador & 48,0 & 38,5 \\
\hline solidário & 46,1 & 44,0 \\
\hline revoltado & 42,3 & 34,0 \\
\hline pacífico & 40,4 & 33,8 \\
\hline honesto & 36,2 & 30,5 \\
\hline malandro & 30,8 & 45,1 \\
\hline violento & 28,5 & 36,7 \\
\hline preguiçoso & 24,0 & 34,9 \\
\hline egoísta & 21,6 & 23,1 \\
\hline desonesto & 17,2 & 19,8 \\
\hline & $(\mathrm{N}=1578)$ & $(\mathrm{N}=1578)$ \\
\hline
\end{tabular}

Fonte: Cpdoc/ISER (1997).

De modo geral, a imagem dos brasileiros não é muito negativa no que se refere a traços psicológicos, na medida em que características como desonestidade, egoísmo, preguiça e violência têm baixa cotação. A auto-imagem dos cariocas é um pouco pior mas não chega a ser comprometedora. Mas o que chama a atenção no conjunto das características mais votadas é a idéia de passividade: trabalho, sofrimento, conformismo. Pior ainda, tudo isto é temperado pela alegria. Pode-se perguntar se não há contradição das pessoas que anotaram ao mesmo tempo 
sofrimento e alegria. Parece-me que não. Sofredor pode indicar a idéia de vítima do governo, das circunstâncias, do destino. A alegria seria a maneira de enfrentar a desgraça. O brasileiro seria um sofredor conformado e alegre. Descrição perfeita desta autopercepção é o nome de um bloco carnavalesco do Recife: "Nóis sofre mas nóis goza". Isto, do ponto de vista moral e psicológico, não compromete, a não ser que se queira ver aí traços de masoquismo. Mas, do ponto de vista político e cívico, é a própria definição do não-cidadão, do súdito que sofre, conformado e alegre, as decisões do soberano. O povo se vê como vítima, como paciente e não como agente da história. Como a vejo, a razão satânica tem sobretudo a ver com esta falta de sentimento cívico.

Há uma característica psicocultural que autores que trabalham com o conceito de cultura política (Almond e Verba, 1965; Inglehart, 1990 e 1997; Kalberg, 1993) consideram central para o funcionamento de um sistema democrático de governo: a confiança nos concidadãos. Compreende-se a estreita vinculação entre confiança mútua e democracia. Pelo menos dentro da visão anglo-saxônica de cidadania, a cooperação, a capacidade de organização, de ação coletiva, é fundamental. É óbvio que sem confiança no próximo não há possibilidade de ação organizada. A pergunta sobre confiabilidade foi feita nas duas pesquisas. Os resultados da pesquisa do Rio estão na Tabela 6.

Os dados são desalentadores. Tendo ou não boa imagem de seus concidadãos, nada menos de $60 \%$ dos entrevistados acham que eles são pouco ou nada confiáveis. Apenas $36,7 \%$ os julgam dignos de confiança. Este é o único ponto em que há grande diferença entre as duas pesquisas. De acordo com VP/Veja, 63\% dos respondentes julgam os brasileiros merecedores de muita confiança e só $34 \%$ os acham pouco ou nada confiáveis, proporções exatamente opostas às da pesquisa do Rio. Os resultados são bons para o Brasil e preocupantes para o Rio de Janeiro. Pode estar refletido nas respostas do Rio o impacto da violência que atinge os moradores dessa região e os faz perder a confiança em seus concidadãos.
Tabela 6

Confiabilidade dos brasileiros (\%)

\begin{tabular}{|c|c|}
\hline $\begin{array}{c}\text { Confiabilidade } \\
\text { muito } \\
\text { confiável }\end{array}$ & 6,5 \\
\hline confiável & 30,2 \\
\hline $\begin{array}{c}\text { pouco } \\
\text { confiável }\end{array}$ & 46,3 \\
\hline não confiável & 13,8 \\
\hline NS/NR & 3,2 \\
\hline total & 100,0 \\
\cline { 2 - 2 } & $\mathrm{N}=1578)$ \\
\hline
\end{tabular}

Fonte: Cpdoc/ISER (1997).

Note-se, no entanto, que mesmo os dados nacionais de confiabilidade estão muito abaixo dos encontrados na maioria das democracias européias. No World values survey de 1990 o Brasil apresenta o mais baixo índice de confiança interpessoal entre os 43 países pesquisados (Inglehart, 1997, pp. 359 e 306). Pesquisas feitas entre 1976 e 1986 na Europa mostram grande estabilidade no grau de confiança dentro de cada país. Além disso, à exceção de Grécia e Itália, o grau de confiança nos concidadãos está entre 85\% e $95 \%$, muito mais alto do que no Brasil e disparadamente mais alto do que no Rio de Janeiro. Sintomaticamente, a confiabilidade mais baixa está na Sićlila e no sul da Itália, em torno de 50\% (Inglehart, 1990, pp. 34-35). Isto lembra imediatamente os estudos de Banfield (1958) sobre o familismo e amoralismo da cultura dessas regiões e a mais recente análise de Putnam sobre sua baixa capacidade cívica (Putnam, 1996). Estudo anterior de Almond e Verba (1965, pp. 212-214) tinha mostrado também grau mais alto de confiança entre os nacionais dos Estados Unidos e GrãBretanha, mais baixo na Alemanha e México, muito baixo na Itália. A estreita correlação entre confiança nas pessoas e longevidade do sistema democrático de governo foi também estabelecida por Inglehart (1997, p. 174). 
O resultado da pesquisa do Rio torna-se ainda mais preocupante quando se faz o controle por idade. Para simplificar a exposição, tomo apenas os dois grupos extremos, o dos jovens entre 16 e 24 anos e o dos maiores de 55 anos. No grupo mais velho, $46 \%$ acham o brasileiro confiável, contra $47 \%$ que acham o oposto. $\mathrm{Na}$ geração mais nova, $74 \%$ não confiam em seus concidadãos, contra apenas $25 \%$ que confiam. A confiança no próximo diminui radicalmente entre os mais jovens, o que não traz boas notícias para o futuro da democracia. A religião também tem efeito sobre a confiança mútua. Os extremos, aqui, estão localizados nas religiões mediúnicas, em que o grau de confiança chega a 50\%, e entre os sem religião, que só confiam na proporção de $27 \%$. Os evangélicos ficam próximos dos que menos confiam (31\%).
Outras variáveis têm efeito discreto sobre a confiança. Como era de esperar, os que pertencem a sindicatos e associações profissionais e beneficentes tendem a apresentar maior confiança no próximo: quem confia se associa. Cor e sexo não afetam o grau de confiança. Grau de informação correlaciona-se positivamente: $45 \%$ dos que lêem mais jornais confiam, contra $35 \%$ dos que não lêem. Pessoas com alguma educação superior também confiam mais $(53 \%)$ do que as que não passaram da $4^{a}$ série $(40,5 \%)$.

A semelhança do caso brasileiro com o sul da Itália no que se refere à falta de civismo é sugerida ainda pelos dados da Tabela 7, que mostram o grau de confiabilidade de algumas lideranças.

Tabela 7

Grau de confiança em lideranças (\%)*

\begin{tabular}{|c|c|c|}
\hline Lideranças & $\begin{array}{c}\text { CPDOC/ISER } \\
\text { Média das notas }\end{array}$ & $\begin{array}{c}\text { VP/VEJA } \\
\text { Média das } \\
\text { notas }\end{array}$ \\
\hline líderes de sua religião & 8,1 & 6,4 \\
\hline parentes & 7,9 & 6,8 \\
\hline amigos & 6,6 & 5,7 \\
\hline vizinhos & 6,0 & 4,7 \\
\hline patrão/empregador & 5,4 & 4,4 \\
\hline presidente do Brasil & 5,1 & 4,7 \\
\hline líderes sindicais e de & 4,2 & 4,0 \\
\hline associações & 4,1 & 3,9 \\
\hline prefeito de sua cidade & 4,0 & 3,1 \\
\hline deputado em quem votou & & \\
\hline
\end{tabular}

*As duas pesquisas pediram que as lideranças fossem avaliadas de 1 a 10 , segundo o grau de confiança que despertavam. A tabela fornece as médias das notas Fonte: VP/Veja e Cpdoc/ISER (1997).

Como se vê, há impressionante semelhança entre os dados nacionais e os da Região Metropolitana do Rio de Janeiro. A ordem de confiabilidade é praticamente idêntica e os valores são próximos. O sentido dos dados é inequívoco: os brasileiros em geral, e os cariocas em particular, confiam em parentes e líderes religiosos, vindo a seguir amigos e vizinhos. É maior a confiança nos patrões do que nas lideranças sindicais. As lideranças políticas, com exceção do 
presidente da República, não merecem confiança. O troféu da desconfiança vai para os deputados em quem os entrevistados votaram. $\frac{17}{}$ Usando a expressão de Roberto Da Matta (1987), inspirada em Gilberto Freyre, os brasileiros só confiam na casa, no mundo das relações primárias. Fora de casa, no espaço público, só merecem confiança os líderes religiosos. Ao final do século XX, a maioria dos brasileiros se mantém avessa ao mundo das associações civis e da política. No Rio, o fenômeno é ainda mais acentuado, seguramente em decorrência da violência que empurra todos para dentro da casa. Se as características do brasileiro descritas na Tabela 5 o aproximam do súdito, as respostas da Tabela 7 o levam para perto do paroquialismo, para usar a terminologia de Almond e Verba, isto é, para uma cultura desvinculada do político, e até mesmo do civil, voltada para o mundo doméstico. Outros dados da pesquisa Cpdoc/ISER confirmam essa característica, mostrando o baixíssimo grau de associativismo da população da Região Metropolitana do Rio de Janeiro. Só $2 \%$ dos entrevistados são filiados a partidos políticos, 5,5\% a associações de moradores, 1,7\% a associações de pais.

Parece-me razoável concluir que tal auto-imagem contribui para a existência e a persistência do motivo edênico. Quem não se vê como um ser civil e cívico não se pode ver como agente, individual ou coletivo, de mudanças sociais e políticas de que se possa orgulhar e deve buscar alhures razões para a construção de uma identidade nacional.

Maior clareza sobre a questão é obtida se examinarmos as razões que o brasileiro tem para ter vergonha do país. As duas pesquisas pediram que os entrevistados indicassem três motivos para se ter vergonha do Brasil. As respostas estão na Tabela 8.

As respostas a essa pergunta foram muito diversificadas. Mas um exame cuidadoso delas mostrou que, de fato, indicavam maneiras distintas de apontar alguns poucos problemas que as pessoas julgam vergonhosos para o país.
Creio não ter violentado as respostas classificando-as nas categorias da tabela, o que não exclui, evidentemente, o uso de outras categorias ou uma classificação diferente. $\mathrm{Na}$ primeira categoria incluem-se respostas como: baixos salários, salário mínimo, fome, favelas, menor abandonado, descaso com os pobres, distribuição de renda, condição financeira, economia, injustiça social, desigualdade, diferença social, falta de oportunidade etc. Isto é, inclui tudo que tenha a ver com a questão social. Poder-se-ia somar a ela o item referente a educação e saúde, tratado à parte apenas por causa da importância dessas duas áreas. Neste último item cabem todas as respostas que têm a ver com deficiências nos sistemas escolar, hospitalar e de saneamento. No item "políticos" foram incluídas respostas do seguinte tipo: governo, governantes, mau governo, o lado administrativo, administração, falta de vergonha das autoridades, falcatruas políticas, classe dirigente, congresso, política, classe política, politicagem, político ladrão, político corrupto, político desonesto, o presidente da República, o prefeito, Collor, ladrões lá de cima, descaso das autoridades etc. Em "corrupção" foram incluídas, entre outras, as seguintes respostas: roubo, roubalheira, roubo no INSS, impunidade, sonegação, falta de vergonha, falta de honestidade, maracutaia, malandragem, falcatruas etc. $\mathrm{O}$ item "corrupção" poderia ser somado ao item "políticos", pois as duas coisas estão freqüentemente relacionadas. A crítica aos políticos quase sempre diz respeito à idéia de corrupção: corrupto, ladrão, desonesto, são adjetivos que, na visão popular, grudam firmemente no substantivo político. Em "violência" compreende-se tudo que tenha a ver com segurança, justiça e polícia: agressões, mortes, assaltos, massacres, chacinas, seqüestros, criminalidade, injustiça, impunidade, falta de segurança, justiça precária, leis não cumpridas, poder judiciário, segurança pública, polícia corrupta etc. Foi classificada em "outros" grande variedade de respostas que vão desde os bailes funks até mulher feia, passando pela dívida externa, drogas, falta de respeito ao próximo, sujeira, jeitinho brasileiro, fila de bancos, racismo, corporativismo, povo sem vergonha, homossexuais, mulheres nuas, prostituição etc. 
Tabela 8

Motivos de vergonha de ser brasileiro (\%)

\begin{tabular}{|c|c|c|c|c|c|}
\hline \multirow{2}{*}{ Motivos } & VP/ & CPDOC/ & VP/ & CPDOC/ & CPDOC/ \\
\cline { 2 - 6 } & VEJA 1 & ISER 1 & VEJA 2 & ISER 2 & ISER 3 \\
\hline $\begin{array}{c}\text { miséria/ } \\
\text { desemprego/ } \\
\text { pobreza }\end{array}$ & 29,0 & 20,1 & 25,0 & 17,4 & 24,9 \\
\hline $\begin{array}{c}\text { saúde/ } \\
\text { educação }\end{array}$ & 3,0 & 3,9 & 6,0 & 5,7 & 8,0 \\
\hline políticos & 18,0 & 21,2 & 14,0 & 11,6 & 16,6 \\
\hline corrupção & 17,0 & 6,0 & 15,0 & 5,0 & 7,2 \\
\hline violência & 9,0 & 19,6 & 11,0 & 14,0 & 19,9 \\
\hline outros & 5,0 & 10,5 & 7,0 & 11,1 & 16,0 \\
\hline nenhum & 8,0 & 4,6 & 5,0 & 5,2 & 7,4 \\
\hline NS/NR & 11,0 & 14,1 & 17,0 & 30,0 & - \\
\hline total & 100,0 & 100,0 & 100,0 & 100,0 & 100,0 \\
\cline { 2 - 6 } & $(\mathrm{N}=1962)$ & $(\mathrm{N}=1579)$ & $(\mathrm{N}=1962)$ & $(\mathrm{N}=4731)$ & $(\mathrm{N}=3320)$ \\
\hline
\end{tabular}

* Como na Tabela 3, VP/VEJA 1 e CPDOC/ISER 1 computam apenas a primeira resposta. VP/VEJA 2 e CPDOC/ISER 2 são a média das três respostas. CPDOC/ISER 3 refere-se às três respostas com eliminação de NS/NR. No caso de VP/VEJA, a resposta "o abandono do menor" foi incluída no primeiro motivo (Veja, 10/1/1996, p. 54).

Fontes: VP/Veja e Cpdoc/ISER.

As razões de vergonha nacional podem, assim, ser concentradas em três grupos, a saber: questões sociais, incluindo-se aí educação e saúde; política e corrupção; segurança. A questão social nas duas pesquisas responde por cerca de 30\% das respostas. Políticos e corrupção ocupam o primeiro lugar como motivo de vergonha quando se leva em conta a primeira resposta. Computandose as três respostas vêm em segundo lugar. Segurança vem em terceiro lugar. Os três motivos juntos respondem por cerca de $70 \%$ das respostas nas duas pesquisas. 18 O Rio de Janeiro salienta-se no quadro nacional por duas características: menor ênfase na corrupção e maior ênfase na segurança.
Se controlarmos as respostas pelo nível educacional, acentua-se seu sentido crítico. Os dados existem apenas para a pesquisa Cpdoc/ISER e estão na Tabela 9.

A grande diferença entre as Tabelas 8 e $\underline{9}$ é o fato de que a educação aumenta muito a capacidade crítica. Quanto mais educada a pessoa, mais capaz de mencionar motivos de vergonha. Mas a sensibilidade crítica dos mais educados é distinta da dos menos educados. Ela é maior em relação a políticos e corrupção e educação e saúde. No item políticos e corrupção, os mais educados comparecem com o triplo das respostas dos menos educados, colocando-o em primeiro lugar entre os motivos de vergonha; no item educação e saúde, com o dobro. A sensibilidade é menor 
em relação a pobreza e violência, que preocupam mais os que ocupam os estratos ocupacionais médios.

Tabela 9

Motivos de vergonha de ser brasileiro por escolaridade (\%)*

\begin{tabular}{|c|c|c|c|c|}
\hline Motivos & $\begin{array}{c}\text { Até a 4a } \\
\text { série }\end{array}$ & $\begin{array}{c}\text { Da 5a à } \\
8 \text { a séries }\end{array}$ & $\begin{array}{c}\text { 2o grau } \\
\text { incompleto/ } \\
\text { completo }\end{array}$ & $\begin{array}{c}\text { 3o grau } \\
\text { incompleto/ } \\
\text { completo }\end{array}$ \\
\hline $\begin{array}{c}\text { miséria/ } \\
\text { desemprego/ } \\
\text { pobreza }\end{array}$ & 12,9 & 19,1 & 19,6 & 18,2 \\
\hline saúde/educação & 3,9 & 5,5 & 6,3 & 9,3 \\
\hline políticos & 8,3 & 10,2 & 14,4 & 19,3 \\
\hline corrupção & 2,5 & 4,3 & 7,1 & 10,2 \\
\hline violência & 12,0 & 15,2 & 16,0 & 10,0 \\
\hline outros & 7,4 & 10,3 & 14,1 & 16,7 \\
\hline nenhum & 10,1 & 5,0 & 2,1 & 0,6 \\
\hline NS/NR & 42,9 & 30,4 & 20,4 & 15,7 \\
\hline total & 100,0 & 100,0 & 100,0 & 100,0 \\
\cline { 2 - 6 } & $(\mathrm{N}=1354)$ & $(\mathrm{N}=1714)$ & $(\mathrm{N}=1191)$ & $(\mathrm{N}=472)$ \\
\hline
\end{tabular}

* Foi usada neste quadro a soma das três respostas, que, como se viu, aumenta o número de NS/NR. Fonte: Cpdoc/ISER (1997).

Se nos motivos de orgulho fatores sociais ou políticos estavam ausentes, nos de vergonha eles têm predomínio absoluto. Quando se trata de diagnosticar os problemas do país, a população é profundamente lúcida. Nem mesmo a má qualidade do brasileiro em geral é mencionada com freqüência entre os motivos de vergonha, exceto entre os mais educados. O que é mau são as instituições, são os governantes e suas políticas. O drama envolvido nas respostas é que os problemas sociais e de segurança apontados dependem do funcionamento das instituições e da ação dos políticos. Ora, os políticos (por extensão, o sistema representativo) são eles próprios um dos principais motivos de vergonha.
Os dados trazem nova luz sobre o curto-circuito que leva ao edenismo. Se os concidadãos são pouco confiáveis, ainda menos confiáveis são os representantes políticos. $\mathrm{O}$ povo não se vê como responsável pelo que acontece no país não apenas porque não participa mas ainda por não se considerar cúmplice da ação de seus representantes, mesmo quando os elege. Não se vê como agente direto nem indireto da política. Não se enquadra na democracia antiga nem na moderna. Desse modo, só lhe restam as belezas naturais, cada vez mais destruídas por ele próprio. No dia em que lhe faltarem as belezas, o último refúgio de orgulho talvez seja o samba e o futebol. "Nóis sofre" na política mas "nóis goza" no Carnaval e nas vitórias da seleção nacional de futebol. 
Hegel, em terrível avaliação, achava que a América, sobretudo a do Sul, estava condenada a ser prisioneira da natureza, a nunca se elevar à condição de história. A sobrevivência de nosso edenismo como substituto da participação se não dá razão ao filósofo, não deixa de ser um dado inquietante. É como inquietação que entendo o desabafo de Nelson Rodrigues ao dizer que o Brasil é uma paisagem. Consola, mas não muito, a existência, registrada também por Nelson Rodrigues, de uma pátria de chuteiras.

\section{NOTAS}

1 Nesta e em todas as outras citações de autores antigos atualizo a ortografia e a pontuação.

2 Uso a citação de João Francisco Lisboa (1865, vol. II, p. 191).

$\underline{3}$ Rocha Pita usa bela expressão ao dizer que para descrever o mapa dilatado que tem pela frente necessita das artes de um pintor, da "viveza das cores", das "valentias do pincel". E vai além na defesa do estilo, dizendo que seu pincel ainda está humilde nas imagens porque trabalhou em parte por informações de outros (ver o Prólogo da obra).

4 A opinião de Aristóteles devia ser moeda corrente na Europa. A ela se refere também frei Vicente do Salvador, cuja obra Pita não devia conhecer pois só foi publicada no século XIX. Frei Vicente argumenta contra Aristóteles dizendo que o calor no Brasil é amenizado pela umidade da terra, pelos ventos que vêm do mar e pelo fato de serem os dias iguais o ano todo. $\mathrm{Na}$ zona temperada, os dias de verão são mais longos, o que redunda em exposição mais extensiva ao sol. Ora, a extensão faz intensão (intensidade). De qualquer modo, diz ele, como Pita mais tarde, a experiência mostra que se vive no Brasil alegremente e sem doenças, exceto algumas bexigas (Salvador, 1982, pp. 6162).

5 Uma seleção desses panfletos foi publicada pelo Conselho Federal de Cultura (1973), com introdução de
Raimundo Faoro. No entanto, centenas de panfletos ficaram de fora e a introdução de Faoro, apesar da qualidade de sempre, é breve e não faz justiça à riqueza do material.

6 Uma das marcas características do Brasil no período da independência, em relação aos outros países da América ibérica, foi a presença da idéia de império. No México ela também surgiu mas teve vida breve. Entre nós, desde que se pensou em independência, e mesmo antes, havia, entre brasileiros e portugueses, a convicção de que aqui se construiria não um reino, como o de Portugal, mas um império. As dimensões do território eram sem dúvida a razão para tal expectativa. Sobre o tema, ver Lyra (1994).

7 Os dois livros foram Scènes de la nature sous les tropiques (1824) e Résumé de l'bistoire litéraire du Brésil (1826). Sobre o tema, ver Roberto Ventura (1991, pp. 29-32).

$\underline{8} \mathrm{O}$ exagero de Veríssimo prova-se pela publicação, durante o Império, de textos de história do Brasil para crianças. O primeiro talvez tenha sido o Resumo da história do Brasil, de H.L. de Niemeyer Bellegarde, adotado pelo governo para uso nas escolas, cuja segunda edição é de 1834. A primeira edição deste livro era, em parte, tradução do Résumé de Ferdinand Denis. Joaquim Manuel de Macedo também escreveu manuais tanto para escolas primárias como para o Colégio Pedro II. É possível, no entanto, que tais obras tenham tido efeito restrito à capital e aos poucos que freqüentavam a escola.

9-Sobre o nacionalismo e o ufanismo na virada do século, ver Lúcia Lippi Oliveira (1990, especialmente pp. 95-109). Figura trágica de ufanista desiludido é a de Policarpo Quaresma, conhecida personagem de Lima Barreto. Uma discussão da literatura infantil do início da República e de seu possível impacto sobre a formação de uma imagem nacional pode ser encontrada em Carvalho (1995).

10 Trata-se de pesquisa nacional feita pela Vox Populi, a pedido da revista $V$ eja, cujos resultados foram publicados em Veja, 10/1/1996, com a assinatura de Ricardo Grinbaum, e de pesquisa realizada em cooperação pelo 
Centro de Pesquisa e Documentação de História Contemporânea do Brasil (Cpdoc) e pelo Instituto de Estudos da Religião (ISER). Veja, na pessoa de Ricardo Grinbaum, e Vox Populi, por seu diretor Marcos Coimbra, concordaram em incluir em sua pesquisa perguntas que permitissem comparação com a do Rio. Deixo aqui meus agradecimentos aos dois. A pesquisa $\mathrm{VP} / V_{\text {eja }}$ foi realizada entre 28 e 31 de outubro de 1995. Foram entrevistadas 1.962 pessoas em amostra aleatória nacional. A margem de erro da amostra é de 3\% e o intervalo de confiança de 95\%. A pesquisa Cpdoc/ISER, intitulada Lei, justiça e cidadania, foi feita sob a coordenação do autor deste artigo, por Leandro Piquet Carneiro, do ISER, Mário Grynszpan e Dulce Pandolfi, do Cpdoc, entre setembro de 1995 e julho de 1996. Baseou-se em amostra aleatória da população de oito municípios da Região Metropolitana do Rio de Janeiro. A amostra foi feita em dois momentos. No primeiro, foram sorteados 6.837 domicílios e cadastradas 16.763 pessoas. Dessas foram entrevistadas 1.578. A margem de erro estimada é de 3,9\% e o intervalo de confiança é de $95 \%$. A pesquisa foi financiada, do lado do Cpdoc, pela Finep e pela Fundação Ford; do lado do ISER, pela Fundação Banco do Brasil. Os principais resultados podem ser encontrados na publicação conjunta do Cpdoc e do ISER (1997), Lei, justiça e cidadania.

11 Ter ou não orgulho do país depende, naturalmente, da conjuntura. Pesquisa nacional DataFolha, feita em setembro de 1991, quando havia denúncias de corrupção contra o governo Collor, revelou que 40\% da população ou não tinha orgulho de nada ou não sabia mencionar qualquer motivo para ter orgulho do país. Sintomaticamente, entre os que mencionaram algum motivo, a maioria (8\%) optou pela natureza. Entre os que tinham curso superior, essa porcentagem subia para 20\%. Cf. Folha de S. Paulo, 22/9/1991.

12 Dados para os Estados Unidos e Inglaterra, de 1959, embora já antigos, servem para mostrar o contraste com o Brasil. Nos dois países, os atributos físicos são pouco mencionados como motivo de orgulho (5\% e 10\%, respectivamente) em comparação com as instituições políticas (85\% e 46\%, respectivamente). Eles aparecem mais na Alemanha (17\%). Mas mesmo nesse país já tinham perdido força em 1978 para instituições políticas (14\% e $31 \%$, respectivamente). Ver Almond e Verba (1980, p. 230).

13 A Semana, 20/8/1893. Agradeço a Paulo Luiz M.C. Esteves a indicação desta crônica de Machado.

14 Sobre o conteúdo da propaganda estado-novista, muito inovador em relação à visão tradicional da elite, ver Ângela de Castro Gomes (1996).

15 O subtítulo do livro de Paulo Prado é sugestivo: Ensaio sobre a tristeza brasileira. O autor cita Capistrano de Abreu, que sugere como símbolo nacional o jaburu, ave grandalhona que passa os dias com uma perna cruzada na outra, triste, triste, triste.

16 Pesquisa nacional da agência de publicidade Propeg, realizada em janeiro de 1998, traz resultados semelhantes. As principais características dos brasileiros, segundo os 1.700 entrevistados, seriam: trabalhador, alegre, acomodado, otimista. O carioca, por outro lado, é visto pelos outros brasileiros como malandro, alegre, preguiçoso, simpático. Jornal do Brasil, 29/3/1998, p. 8.

17 A desconfiança e mesmo o desprezo por políticos aparecem em quase todas as pesquisas que tratam do assunto. Apenas como exemplo, pesquisas do Ibope realizadas entre 1988 e 1990 colocam sistematicamente os políticos como os menos confiáveis entre várias categorias sociais e instituições. Em seis pesquisas realizadas no período, a parcela de entrevistados que confia nos políticos fica em torno de $15 \%$, em contraste com os $80 \%$ que confiam na Igreja Católica. Ver Lamounier e Marques (1992, p. 146).

18 A pesquisa da Propeg, já referida, traz resultados semelhantes. Entre as razões de vergonha predominam os problemas sociais, seguidos da corrupção dos políticos e da segurança. Cf. Jornal do Brasil, 29/3/1998. Nessa pesquisa, os políticos aparecem como a categoria social que menos contribui para o país. 


\section{BIBLIOGRAFIA}

AFONSO CELSO. (s/d.), Porque me ufano do meu país. 8a ed., Rio de Janeiro, Garnier.

ALMOND, Gabriel A. e VERBA, Sidney. (1965), The civic culture. Political attitudes and democracy in five nations. Boston/Toronto, Little Brown.

(eds). (1980), The civic culture revisited. Boston/Toronto, Little Brown and Co.

ARARIPE JR. (sob o pseudônimo de Cosme Velho). (1909), Diálogos das novas grandezas do Brasil. Rio de Janeiro, Tip. do Jornal do Commércio

ASSIS, Machado de. Obras completas. A Semana (18921893). Rio de Janeiro/São Paulo/Porto Alegre, W.M. Jackson Inc., $1^{\circ}$ vol.

BANFIELD, Edward. (1958), The moral basis of a backward society. Chicago, Free Press.

BELLEGARDE, H.L. de Niemeyer. (1834), Resumo da história do Brasil. $2^{a}$ ed., Rio de Janeiro, Typographia de R. Ogier.

BOMENY, Helena Maria Bousquet. (1981), Paraíso tropical: a ideologia do civismo na TVE do Maranhão. Rio de Janeiro, Achiamé.

CÂNDIDO, Antônio. (1981), Formação da literatura brasileira. $2^{a}$ ed., Belo Horizonte, Itatiaia, 2 vols.

CARVALHO, José Murilo de. (1995), "Brasil: nações imaginadas". Antropolitica, 1: 7-36.

CONSELHO FEDERAL DE CULTURA. (1973), O debate político no processo da independência. Rio de Janeiro, CFC.

CPDOC-FGV/ISER. (1997), Lei, justiça e cidadania. Rio de Janiero, Cpdoc-FGV/ISER.
DA MATTA, Roberto. (1987), A casa e a rua. Rio de Janeiro, Ed. Guanabara.

DLÁLOGOS das grandezas do Brasil. (1977 [1618]), São Paulo/Brasília, Melhoramentos/INL.

FICO, Carlos. (1997), Reinventando o otimismo. Ditadura, propaganda e imaginário social no Brasil. Rio de Janeiro, Ed. da Fundação Getúlio Vargas.

GANDAVO, Pero de Magalhães. (1980), Tratado da terra do Brasil e História da Provincia Santa Cruæ. Belo Horizonte/São Paulo, Itatiaia/EDUSP.

GERBI, Antonello. (1996), O novo mundo. Tradução de Bernardo Joffily. São Paulo, Cia. das Letras.

GOMES, Ângela de Castro. (1996), História e historiadores. A política cultural do Estado Novo. Rio de Janeiro, Ed. da Fundação Getúlio Vargas.

HOLANDA, Sérgio Buarque de. (1959), Visão do paraíso. Os motivos edênicos no descobrimento e colonização do Brasil. Rio de Janeiro, José Olympio.

INGLEHART, Ronald. (1990), Culture shift in advanced industrial society. Princeton, Princeton University Press.

(1997), Modernization and postmodernization. Cultural, economic, and political change in 43 societies. Princeton, Princeton University Press.

KALBERG, Stephen. (1993), "Cultural foundations of modern citizenship", in Bryan S. Turner (ed.), Citizenship and social theory, Londres, Sage Publications, pp. 91-114.

LAMOUNIER, Bolívar e MARQUES, Alexandre $\mathrm{H}$. (1992), "A democracia brasileira no final da ‘década perdida"', inBolívar Lamounier (org.), Ouvindo o Brasil. Uma análise da opinião pública brasileira hoje, São Paulo, Ed. Sumaré/Instituto Roberto Simonsen, pp.137-158.

LISBOA, João Francisco. (1865), Obras. São Luiz do Maranhão, Typ. de B. de Mattos, 4 vols. 
LYRA, Maria de Lourdes Viana. (1994), A utopia do poderoso império. Portugal e Brasil: bastidores da politica, 1898-1822. Rio de Janeiro, Sette Letras.

MELO FRANCO, Afonso Arinos de. (1937), O indio brasileiro e a Revolução Francesa. Rio de Janeiro, José Olympio.

OLIVEIRA, Lúcia Lippi. (1990), A questão nacional na Primeira República. São Paulo, Brasiliense.

PRADO, Paulo. (1931), Retrato do Brasil. Ensaio sobre a tristeza brasileira. 4a ed., Rio de Janeiro, Briguiet.

PUTNAM, Robert D. (1996), Comunidade e democracia: a experiência da Itália moderna. Rio de Janeiro, Ed. da Fundação Getúlio Vargas.

ROCHA PITA, Sebastião da. (1730), História da América Portuguesa desde o anno de mil e quinhentos, do seu descobrimento, até o de mil e setecentos e vinte e quatro. Lisboa Occidental, Officina de Joseph Antônio da Silva

RODRIGUES, Nelson. (1997), A cabra vadia. Novas confissões. São Paulo, Cia. das Letras.

ROMERO, Sílvio. (1943), História da literatura brasileira. $3^{\mathrm{a}}$ ed., Rio de Janeiro, José Olympio.

SALVADOR, frei Vicente do. (1982), História do Brasil, 1500-1627. $7^{\mathrm{a}}$ ed., Belo Horizonte/São Paulo, Itatiaia/EDUSP.

VENTURA, Roberto. (1991), Estilo tropical. História cultural e polêmicas literárias no Brasil. São Paulo, Cia. das Letras.

VERISSIMO, José. (1906), A educação nacional. Rio de Janeiro, Francisco Alves. 